\title{
The historical global sea-level budget
}

\author{
J.C. MOORE, ${ }^{1,2}$ S. JEVREJEVA, ${ }^{3}$ A. GRINSTED ${ }^{4}$ \\ ${ }^{1}$ College of Global Change and Earth System Science, Beijing Normal University, Beijing 100875, China \\ E-mail: john.moore.bnu@gmail.com \\ ${ }^{2}$ Arctic Centre, University of Lapland, PO Box 122, FIN-96100 Rovaniemi, Finland \\ ${ }^{3}$ National Oceanography Centre, Joseph Proudman Building, 6 Brownlow Street, Liverpool L3 5DA, UK \\ ${ }^{4}$ Centre for Ice and Climate, Niels Bohr Institute, University of Copenhagen, Juliane Maries Vej 30, \\ DK-2100 Copenhagen, Denmark
}

\begin{abstract}
We analyze the global sea-level budget since 1850. Good estimates of sea-level contributions from glaciers and small ice caps, the Greenland ice sheet and thermosteric sea level are available over this period, though considerable scope for controversy remains in all. Attempting to close the sea-level budget by adding the components results in a residual displaying a likely significant trend of $\sim 0.37 \mathrm{~mm} \mathrm{a}^{-1}$ from 1955 to 2005 , which can, however, be reasonably closed using estimated melting from unsurveyed high-latitude small glaciers and ice caps. The sea-level budget from $\mathbf{1 8 5 0}$ is estimated using modeled thermosteric sea level and inferences from a small number of mountain glaciers. This longer-term budget has a residual component that displays a rising trend likely associated with the end of the Little Ice Age, with much decadal-scale variability that is probably associated with variability in the global water cycle, ENSO and long-term volcanic impacts.
\end{abstract}

\section{INTRODUCTION}

The relative importance of mass and volume change to sealevel rise is of great practical as well as pure scientific interest since their relative response to climate forcing may be very different. We may expect that a change in volume associated with rising temperatures will be relatively smooth, while potential ice-sheet instabilities may produce very rapid and large changes in sea level. The relative mass and volume change is also of interest because it takes $\sim 50$ times more energy to raise sea level by ocean heating than by ice melting (Trenberth, 2009).

There are two main methods of estimating sea-level rise. (1) The contribution from each component of the system can be estimated: glaciers and small ice caps (GSIC), the Greenland ice sheet (GIS), the Antarctic ice sheet, thermal expansion (TS), and changes in terrestrial storage (T). (2) The total observed by tide gauges, complemented since 1993 with satellite altimeter measurements, can be estimated. If these two estimates agree, then we call the sea-level budget closed. Some authors claim that the sealevel budget is closed (Domingues and others, 2008), despite, or perhaps utilizing, the large errors involved in the contributors, but others claim that the best estimates of the relative contributions leave a significant discrepancy with observed sea level (Jevrejeva and others, 2008b).

In this paper, we provide estimates of the various contributions and discuss how close the sum of the parts is to the observed total sea-level rise. We show that the best estimates of the sea-level components result in a satisfactory agreement with observed sea level since 1955 only if we include estimates for polar small glaciers (PSG) from indirect modeling, which seem to have been subject to mu'ch more negative mass balance than more temperate glaciers. We also discuss the much less well-studied, uncertain earlier sea-level component records from 1850 to 1950 . Despite the uncertainties, some plausible features of the record may be extracted.

\section{DATA}

We utilize 1023 time series of monthly mean relative sea level (RSL) from the Permanent Service for Mean Sea Level (PSMSL) database (Woodworth and Player, 2003). RSL datasets were corrected for local datum changes and glacial isostatic adjustment (GIA) of the solid Earth (ICE 4G, VM2; Peltier, 2001). We use a global sea-level (GSL) curve based on the 'virtual station' method (Jevrejeva and others, 2006) which overcomes geographical bias by accounting for the spacing between stations in creating sea-level curves for each of 13 ocean basins. Since about 1950, coverage by tide gauges has been very thorough, but especially in the 18th and 19th centuries there were very few tide gauges, and all were located in Europe, so the issue of how representative a particular tide gauge station in only one basin is of GSL variations was estimated using bootstrap methods (Grinsted and others, 2009). Our GSL trend estimate of $2.4 \pm 1.0 \mathrm{~mm} \mathrm{a}^{-1}$ for the period 1993-2000 is comparable with the $2.6 \pm 0.7 \mathrm{~mm} \mathrm{a}^{-1}$ sea-level rise calculated from TOPEX/Poseidon altimeter measurements (Grinsted and others, 2009). The GSL curve also produces good estimates of the volcanic impacts on sea level (Grinsted and others, 2007), and has been used to reconstruct sea level over the past 2000 years (Grinsted and others, 2009; Jevrejeva and others, 2009). The GSL reconstruction (together with calculated errors) is available from http://www.psmsl.org/ products/reconstructions/jevrejevaetal2006.php

Steric sea level is based on estimates of Global Ocean Heat Content $(\mathrm{GOHC})$ data and is discussed by Levitus and others (2009) for the period 1955-2008. This time period was affected by systematic errors in the heat measurements from the Argo profiling float data that were included in earlier heat-content estimates (e.g. Levitus and others, 2005). We use several estimates of steric sea level derived from the ocean heat-content data, but mainly rely on the values from Domingues and others (2008), where we have added $20 \%$ to the $0-700 \mathrm{~m}$ steric sea-level values, as those authors suggest, to account for the deeper ocean contribution. We return to 
this contentious issue later. We also make use of an estimate of steric sea level from a climate model (Gregory and others, 2006) to extend the record back in time to 1850.

Data on past variations in GSIC come from Cogley (2009). We also estimate GSIC from the independent data on glacier termini positions from Oerlemans and others (2007). This compensates for the very sparse data on glacier mass-balance estimates available prior to 1950 from Cogley (2009): prior to the 1910s, all measurements come from Swiss glaciers, only supplemented between the 1910s and the 1930s from Scandinavian glaciers. The GSIC have been consolidated into 5 year global averages of mass balance of glaciers from outside Greenland and Antarctica based on both direct glaciological surveys and geodetic surveys that together are quite reliable back to about 1955 . A crucial point is how the dataset is extended to include the virtually unsampled smaller polar glaciers. Kaser and others (2006) give three possible estimates based on correlations with either the whole dataset of measured glaciers or glaciers in Canada. In contrast, Hock and others (2009) use mass-balance modeling based on available meteorological station data to estimate the regional mass balance of under-sampled PSG. They computed a rate of $0.28 \pm 0.17 \mathrm{~mm} \mathrm{a}^{-1}$ for the period 19612004, and we use this rate for the 1955-2005 period.

Data on Greenland mass-balance (GIS) history come from Rignot and others (2008a). The GIS was sporadically surveyed typically by leveling across coast-to-coast transects in the early 20th century, but more complete direct observations were carried out in 1958. Cogley (2009) computed the mass balance in 5 year blocks for GSIC, and to make the data more comparable between the different sources we do the same for TS and GIS (assuming for GIS that the 1955-60 balance is the same as the 1958 measurement). This has the impact of removing much seasonal variability, hemispheric differences and noise due to annual snow accumulation variations. Post-1955 5 year 95\% confidence intervals are $<20 \%$ of the mass-balance estimates in GSIC (Cogley, 2009). The mass-balance estimates are summed to produce a relative sea-level curve over time in the figures we show to allow comparison with the GSL curve from tide gauges. We compute the error in GSL as the yearly standard error/ $\sqrt{N-1}$ since autocorrelation within $N=5$ yearly blocks can be neglected and the data assumed to be independent.

\section{RESULTS}

In Figure 1 and Table 1 we show the major components of the 1955-2005 sea-level budget, and their sum compared with the GSL and its error. Since for most components

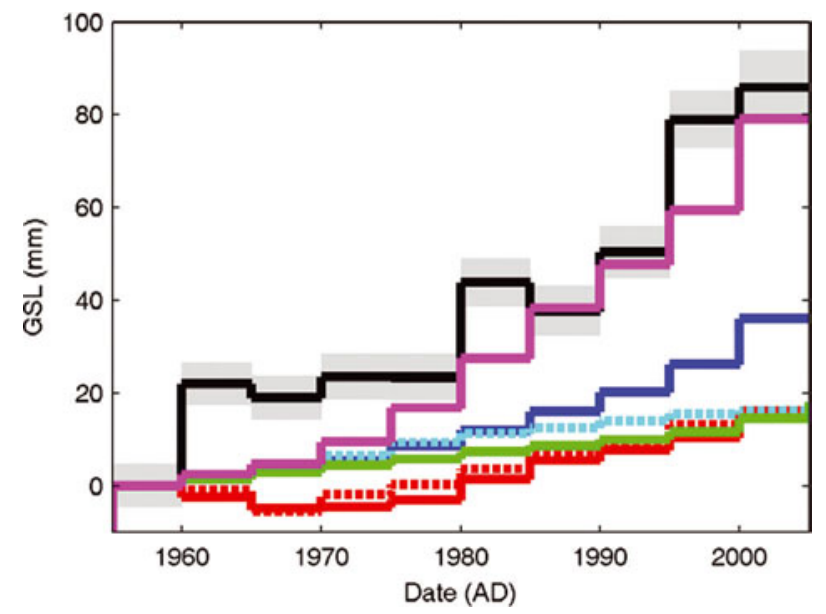

Fig. 1. Time series of anomalies in sea-level components from 1955 to 2005. GSL (black, with standard error as grey shaded region (Jevrejeva and others, 2006)); TS (red solid line, from Domingues and others (2008) corrected for full ocean depth); modeled thermosteric (red dotted line (Gregory and others, 2006)). Cumulative mass balance as sea-level equivalents for: GSIC (blue; Cogley, 2009), GIS (green; Rignot and others, 2008a) and mountain glacier termini (cyan; Oerlemans and others, 2007). Also shown are summed components (TS + GSIC + GIS + PSG; magenta). The 1955-60 period is the baseline for all datasets.

accurate data exist only since about the mid-1950s, we use 1955 as the reference year. Also shown in Figure 1 is the estimation of TS from the climate model; the agreement of the curve with the Domingues and others (2008) curve based on observations is reasonably close, at least in general shape and magnitude. Several things are clear from the plot:

1. GSL is not particularly well correlated with TS (this has also been discussed by Jevrejeva and others, 2008). Despite corrections to the GOHC dataset (e.g. Levitus and others, 2009), this remains the case.

2. Despite a considerable acceleration in mass loss from both the GIS and GSIC since 2000, the sea-level budget constructed using only GIS + GSIC + TS has a residual trend significant at the $93 \%$ level and amounting to $0.36 \mathrm{~mm} \mathrm{a}^{-1}$, with a standard error of $0.18 \mathrm{~mm} \mathrm{a}^{-1}$, accounting for $36 \%$ of the variance of the residual GSL. The sea-level budget can, however, be closed so that the residual trend is wholly insignificant by including the estimated contribution trend from polar small glaciers and ice caps (PSG) from Hock and others (2009).

Table 1. Contributions to the sea-level budget from 1955 to 2005

\begin{tabular}{|c|c|c|c|}
\hline Component & Source & $\begin{array}{c}\text { 1955-2005 rise } \\
\text { mm }\end{array}$ & $\begin{array}{c}\text { Rate } \\
\mathrm{mm} \mathrm{a}^{-1}\end{array}$ \\
\hline GSL (observed) & Jevrejeva and others (2006) & $86(78-94)$ & $1.72(1.56-1.88)$ \\
\hline Thermosteric (TS) & Domingues and others (2008) & 16 & 0.32 \\
\hline Small glaciers (GSIC) & Cogley (2009) & 36 & 0.72 \\
\hline Greenland (GIS) & Rignot and others (2008a) & 14 & 0.28 \\
\hline Polar small glaciers (PSG) & Hock and others (2009) & 14 & 0.28 \\
\hline $\mathrm{TS}+\mathrm{GSIC}+\mathrm{GIS}+\mathrm{PSG}$ & & 80 & 1.60 \\
\hline
\end{tabular}




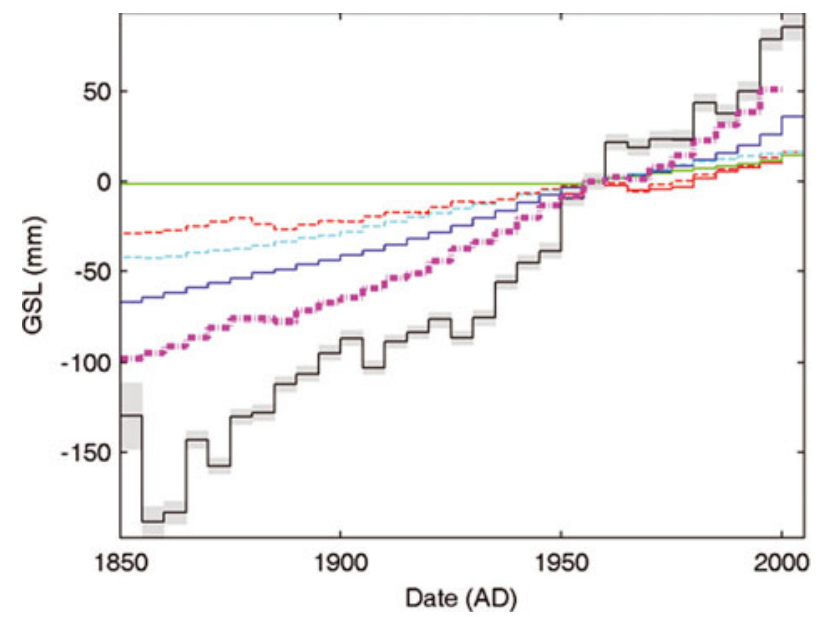

Fig. 2. Time series of anomalies in sea-level components from 1850 to 2005. Curves are as for Figure 1, with summed components (magenta dotted: modeled TS + GSIC + GIS). GIS is assumed to be zero prior to 1955 , so the sum is just the blue and red dotted contribution from GSIC and modeled TS.

3. The TS component is a much smaller component of GSL than GSIC. Indeed it is of similar magnitude to the mass loss from Greenland, or estimates of the contribution from polar mountain glaciers (Table 1 ).

We investigate the longer-term sea-level budget in Figure 2 where we make use of an extended record of GSIC taken from both Oerlemans and others (2007) and the approximately twice as large estimate from Cogley (2009), together with the modeled TS component from Gregory and others (2006). It is clear from this plot that:

1. The TS component remained a small fraction of the sealevel budget back to the mid-19th century, where tidegauge observations are sparse and errors in GSL become much larger than for the more recent part of the record.

2. The sea-level budget can be much better closed using the rates from Cogley (2009) than those from Oerlemans and others (2007), and this would be true of whatever shape factor was used for the geometrical conversion of glacier termini position to glacier volume (Oerlemans and others, 2007).

3. The rate of GSL rise between 1930 and 1950 was about as fast as in the post-2000 period, $\sim 3 \mathrm{~mm} \mathrm{a}^{-1}$. The sealevel curve is consistent with an accelerating trend of $0.01 \mathrm{~mm} \mathrm{a}^{-2}$ from about 1800; superimposed on the long-term acceleration are quasi-periodic fluctuations with a period of $\sim 60$ years (Jevrejeva and others, 2008a). The only contributing information available is GSIC (though much less reliably than since 1955 (Cogley, 2009)). Figure 2 shows that GSIC were not likely to be the main factor in the rapid rise of GSL at that time. The rather slow changes in TS since 1955 suggest that rapid thermosteric response could only be responsible for the GSL changes if there were dramatic changes in ocean circulation. This implies that other sources of mass were most likely the cause of rising GSL: either from Greenland, as has been postulated during the warm 1920s and 1930s by Rignot and others (2008a), Antarctica or other smaller high-latitude glaciers.

\section{DISCUSSION 1955-2005 interval}

We have shown that the sea-level budget may be reasonably closed using the PSG contribution estimated by Hock and others (2009). Support for this also comes from exploring the components of the budget with multiple linear regression. When we do this with TS, GSIC and GIS as forcing variables (and not including any trend for PSG), we find that TS (from Domingues and others, 2008) has an unphysical, negative coefficient of $-1.2 \pm 1.1$, whereas we would expect a coefficient of 1 . This is a marginally significant result. If we drop TS from the GSL forcing factors then the coefficient for GIS dominates $(3.7 \pm 1.8)$ that from GSIC $(1.1 \pm 1)$. This could be interpreted as suggesting that it is the GIS, or factors that correlate with it, that may be responsible for the missing sea-level component. Hock and others' (2009) consideration of the polar glacier contribution suggested that most of the contribution was from the Antarctic Peninsula region $\left(0.22 \pm 0.16 \mathrm{~mm} \mathrm{a}^{-1}\right)$, while the marginal Greenland and other High Arctic glaciers contributed much less. This finding would also be consistent with the inference of unaccounted melting from analyzing the Earth's rotation (Mitrovica and others, 2006), and with evidence of freshening of the oceans (Ishii and others, 2006). Nevertheless the underlying driving force for the ice loss was the relatively greater warming trend in summer temperatures both in the Antarctic Peninsula and, since the 1990s, over Greenland (Rignot and others, 2008a; Hock and others 2009).

Observed sea level is complicated by many other forcing factors such as El Niño Southern Oscillation (ENSO), ocean dynamics and global water cycle, so the detailed observed response to individual eruptions contains very high noise. Grinsted and others (2007) showed that the impact of volcanic activity on sea level was not simply a depression due to global cooling in the years after an eruption, but also a modification of the global water budget such that sea level rises significantly in the first year, followed later by a fall. Large volcanic eruptions inject aerosols into the stratosphere, and these aerosols reflect sunlight, causing global dimming and thus lower temperatures at the Earth surface. The cooling of the ocean surface causes less evaporation. As water flux from terrestrial reservoirs and river discharge continue, the combination of less evaporation and water flux results in a GSL rise of $6-12 \mathrm{~mm}$ during the first year following the eruption. After $\sim 1$ year, stratospheric aerosols have been removed and evaporation reaches normal values. However, the river discharge is now reduced due to the low precipitation in the preceding year, so sea level drops by 4-10 $\mathrm{mm} \mathrm{2-3}$ years after the eruption. This interpretation is supported by observations of large reductions in both land precipitation and continental discharge following major volcanic eruptions (Trenberth and Dai, 2007), and modeled reductions in terrestrial storage caused by reductions in precipitation (Milly and others, 2003).

The timing of volcanic eruptions is unaffected by the ENSO phase. Some eruptions will by chance occur in El Niño years. In contrast, it is plausible that an eruption would have some impact on the ENSO system; perhaps the cooling weakens the trade winds (a weakening being a precursor to El Niño events). We do not argue that volcanic eruptions trigger El Niño events; rather, we argue that it is important to not exclude the possibility of a volcanic influence on the ENSO system. 


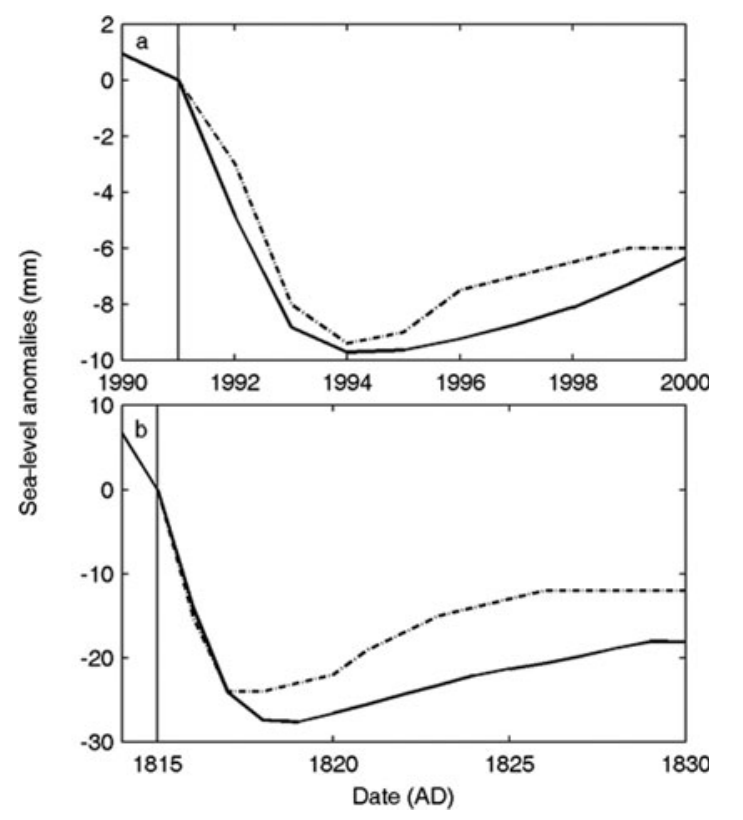

Fig. 3. Stenchikov and others (2009) (dashed curve) and our model (solid curve) sea-level anomaly responses to the Pinatubo 1991 eruption (a) and the Tambora 1815 eruption (b). Anomalies calculated relative to the sea level in the eruption year. Vertical line in both panels corresponds to the year of volcanic eruption.

Interdecadal and multi-year variability in sea level has been attributed to ENSO and volcanic forcing. While the immediate atmospheric impacts of a large volcanic eruption tend to decay within a few years as stratospheric aerosol is removed (Robock, 2000), it has been realized that the impact on the oceans may be much more pervasive and could last a decade or more. Stenchikov and others (2009) use the CM2.1 climate system model to estimate the sealevel response of the large Tambora (Indonesia) 1815 and Pinatubo (Philippines) 1991 eruptions. The sea-level response is essentially determined in the Stenchikov model by the global ocean heat content change. To help interpret and attribute the causes of sea-level rise further, we use a semiempirical model (Jevrejeva and others, 2010) that realistically matches observed sea level over a range of timescales from multi-year to centennial scales. Figure 3 shows the Stenchikov modeled response compared with the model of sea level fitted to the GSL tide-gauge data. This means that for Tambora the model of Jevrejeva and others (2010) must extrapolate well beyond the magnitude of volcanic eruptions observed over most of the tide-gauge measurement interval. Notice that both models predict about the same maximum response, the timing of the maximum drop, and have similar recovery curves. The Tambora response is about three times the Pinatubo response in both models. It is also clear that the volcanic response is primarily determined by heat content change rather than mass of ocean water on multi-year timescales. It also seems to be the case that our model produces a deeper drop than the Stenchikov model, perhaps because our model implicitly incorporates the full system response rather than simply ocean heat content.

The reduction in radiative forcing due to eruptions for the period 1880-2000 was estimated by Jevrejeva and others (2009) to amount to a reduction of $7 \mathrm{~cm}$ in GSL relative to the level it would have reached had no eruptions occurred. The effect of the three large eruptions of the post-1955

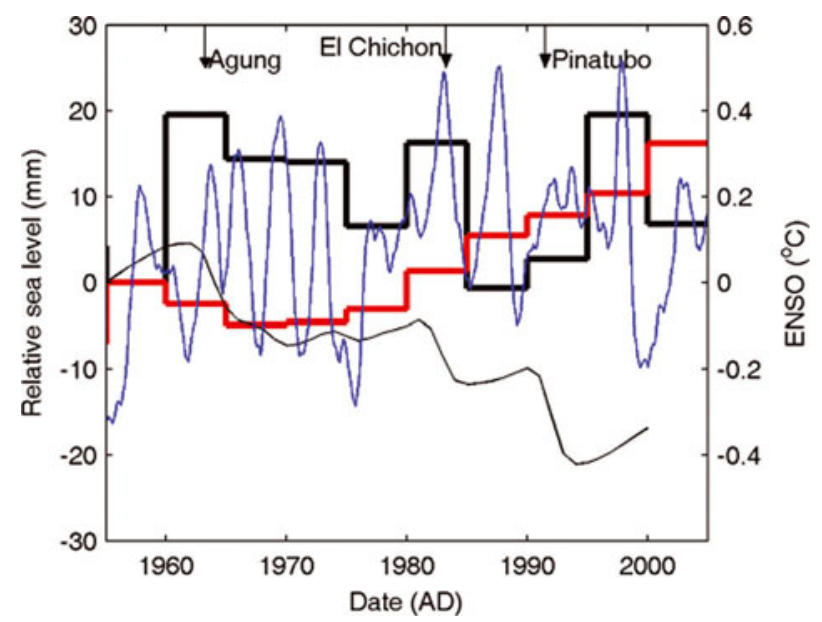

Fig. 4. Residual sea level (GSL-TS-GIS-GSIC-PSG; thick black line), TS (red line) and modeled sea-level response to volcanism (thin black curve). Also plotted is 12 month smoothed ENSO as calculated in the text (blue curve, right-hand scale).

period (Agung (Indonesia) 1963, El Chichón (Mexico) 1982 and Pinatubo 1991) was a depression in sea level for 5-10 years of $\sim 5-10 \mathrm{~mm}$ (Fig. 4) each.

We use an estimate of ENSO activity (http://jisao. washington.edu/data/globalsstenso/globalsstenso18002010. ascii) calculated as the average sea surface temperature (SST) anomaly equatorward of $20^{\circ}$ latitude (north and south) minus the average SST poleward of $20^{\circ}$, which captures the low-frequency part of the ENSO phenomenon. Anomalies are with respect to the period 1950-79. The number of observations contributing is at least 1000 in each month and year beginning in the 1850 s. The choice to calculate the index as the difference of two time series removes a spurious step-jump in SST observations at the onset of World War II that is associated with changes in measurement practices (Folland and Parker, 1995). The difference also removes the common portion of the trend in SST.

In Figure 4 we examine the residual sea level together with the ENSO index, and the Jevrejeva and others (2010) model response of sea level to volcanic forcing. While we plot the ENSO and volcanic sea level as curves in Figure 4, we resampled to pentads and computed multiple linear regression. We find a relationship between residual GSL and volcanic forcing significant at the $97 \%$ level. Figure 4 shows that the 1965-70 and 1985-90 volcanic intervals were associated with a clearly falling GSL residual, while the 1995-2000 strong rise in residual sea level is suggestive of the post-Pinatubo drop and recovery. The impact on thermosteric sea level is much less obvious, despite the obvious mechanistic link between TS and volcanic forcing. This may suggest some problems with the TS dataset used.

\section{0-1950 period}

In Figure 5 we look at the residuals of GSL since 1850. Perhaps the most noticeable feature, though, is the large, $\sim 45 \mathrm{~mm}$ jump in GSL residual that occurs between 1950 and 1960. There is no significant trend for the periods 190050 or 1955-2005 (Fig. 4) if this almost step change is removed. While this feature may be purely errors in the various components, it is also interesting to note this occurs during a period when TS reaches a local maximum. The step change in residual GSL also corresponds to a period when 


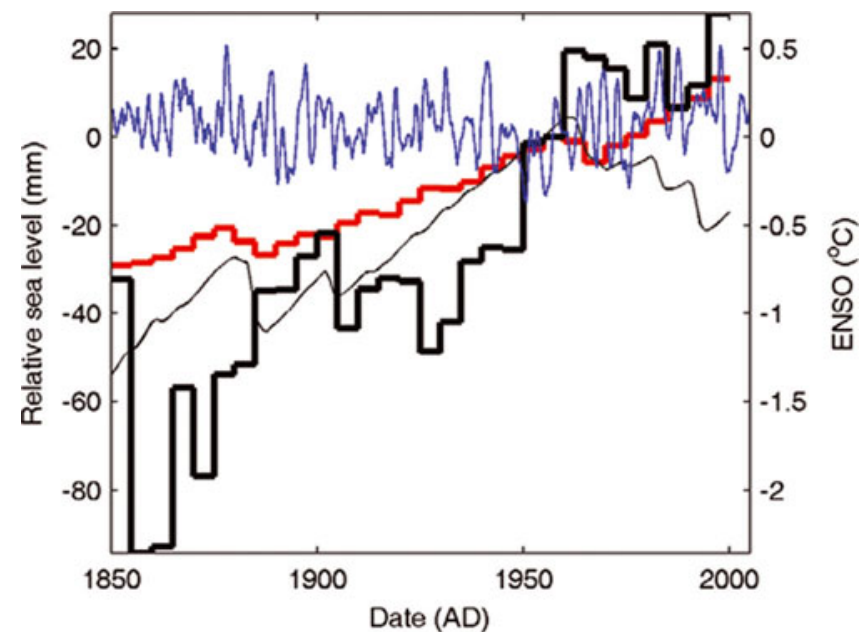

Fig. 5. Modeled thermosteric sea level (red; Gregory and others 2006), and residual sea level (thick black line) calculated as GSLmodeled TS-GSIC (Cogley, 2009). SPG, GIS and Antarctic contributions are assumed to be zero throughout. The volcanic component is represented as in Figure 4 by the thin black curve. The blue curve shows 12 month smoothed ENSO (right-hand scale) calculated as in the text.

volcanic activity was very low and the ENSO index is at its most negative during the entire record. Since ENSO activity and heat content are closely related to ocean circulation patterns, the step change may be associated with changing ocean circulation rather than, say, changes in the ice sheets. The 1855-1900 period has a residual that amounts to about the same as the sum of the TS and GSIC components $(\sim 35 \mathrm{~mm})$, only accounting for about half the observed sealevel rise (Fig. 2). The generally rising trend from 1850 to 1900 may be a reaction to the termination of the Little Ice Age, when glacier retreat was widespread, and may have included the large ice sheets as well as the smaller highlatitude glaciers. This is hard to estimate with any reasonable modeling at present since temperature data from the high latitudes are very sparse or non-existent in the 19th century.

There are highly significant relationships between GSL residual and volcanic forcing of sea level and with ENSO and also North Atlantic Oscillation (NAO, not shown). Thermosteric modeled sea level is significantly affected by volcanic forcing and marginally significantly affected by either ENSO or NAO. Thermosteric sea level is also strongly significantly related to volcanic sea-level variability, and marginally significantly related to ENSO variability.

The amplitude of decadal oscillations in residual GSL is $\sim 20 \mathrm{~mm}$ since about 1870, a similar amount to the post1955 residual, some of which is likely due to unaccountedfor melt from both the small polar glaciers and the Greenland ice sheet, though observed rates of increased melting since 2000 are far less than the observed amplitude of fluctuations. This variability suggests that errors are indeed, as expected, much larger pre-1955 in the sea-level budget components.

\section{UNCERTAINTIES}

\section{Thermosteric sea level}

The main source of ocean heat measurements is the set discussed and updated by Levitus and others (2009), though
Ishii and Kimoto (2009) supplement these with other data. The reduced salinity of the oceans contributing to thermosteric rise is estimated to be much lower than that caused by rising heat content (Ishii and others, 2006). Widely varying estimates of the rate of increase of $\mathrm{GOHC}$ have been derived: for example, linear trends for the 1969-2003 period, when measurements were made mainly by one type of instrument, range from (with 95\% confidence intervals) $0.24 \pm 0.04$ (Ishii and Kimoto, 2009) to $0.41 \pm 0.06 \times 10^{22} \mathrm{Ja}^{-1}$ (Domingues and others, 2008). These differences depend on the method used to produce global rates from the spatially inhomogeneous dataset.

A key element of the steric sea-level rise component is the contribution from the deep ocean below $700 \mathrm{~m}$ depth. To date, little is known about this component. Antonov and others (2005) suggest that steric sea-level rise is $\sim 0.4 \mathrm{~mm} \mathrm{a}^{-1}$, with the deeper ocean contributing only $\sim 0.1 \mathrm{~mm} \mathrm{a}^{-1}$. Domingues and others (2008) used the approximate ratio of steric sea-level rise for the deeper ocean relative to the upper $700 \mathrm{~m}$ to correct their steric sea level derived from the upper $700 \mathrm{~m}$ alone. But, since their steric sea-level rise was already $\sim 50 \%$ larger than earlier estimates (Antonov and others, 2005; Levitus and others, 2005; Ishii and others, 2006), Domingues and others (2008) added a further $\sim 0.2 \mathrm{~mm} \mathrm{a}^{-1}$ for the deeper ocean, resulting in almost a doubling relative to other estimates. This correction may be unsound, as there may be areas where the deep-water contribution is in opposition to the upper part of the water column. Direct estimates of GOHC may well be biased because of large data gaps in the Southern Hemisphere.

Domingues and others (2008) reconstructed GOHC, and Church and White (2006) global mean sea level, using a variant of the optimal interpolation scheme by Kaplan and others (2000). The leading empirical orthogonal functions (EOFs) were determined from 12 years (1993-2004) of detrended TOPEX/Poseidon and Jason-1 satellite altimeter data. The principal components of the leading EOFs were then determined in a least-squares manner to fit the tidegauge observations.

We note that the last 15 years have been exceptionally warm compared with the historical records and that the EOF patterns may not be representative of the patterns prevailing earlier in the century. Kaplan and others (2000) caution against using too short a time period for calculating the EOFs: 'To obtain faithful field reconstructions, we have to use a relatively long time period for the covariance estimation, and there should be enough data in it for estimating all necessary cross covariances.'

\section{Terrestrial water budget}

Vermeer and Rahmstorf (2010) used the results from Chao and others (2008) to estimate potential contribution from water impoundment in the world artificial reservoirs. However, Chao and others (2008) focused on an estimation of contributions that decrease sea-level rise (storage in reservoirs) only, amounting to about $-0.44 \mathrm{~mm} \mathrm{a}^{-1}$. There are, however, several processes that were not considered by Chao and others (2008), and they all lead to higher sea levels. The processes that increase sea level include groundwater mining, estimated as contributing 0.55$0.64 \mathrm{~mm} \mathrm{a}^{-1}$ between 1990 and 1995 by Shiklomanov (1997), and urbanization with a contribution of $0.3 \mathrm{~mm} \mathrm{a}^{-1}$ (Gornitz, 2001). According to Sahagian (2000), the sum of 
the above effects could be of the order of $0.05 \mathrm{~mm} \mathrm{a}^{-1}$ sealevel rise over the past 50 years, with an uncertainty several times as large.

In addition, Lettenmaier and Milly (2009) provide a stateof-the-art estimation of the contributions from continental mass losses/gains: 'We would find it difficult to refute convincingly, on the basis of observations, the proposition that land, overall, contributes essentially nothing to sea-level rise today'.

However, we suggest that decadal variability in sea level is likely to be associated with variability in global water cycle. Changes of $5 \%$ in global river discharge (Fekete and others, 1999) correspond to $5 \mathrm{~mm} \mathrm{a}^{-1}$ in GSL, similar to changes in GSL associated with El Niño or a large volcanic eruption (Grinsted and others, 2007). In addition, changes in $\mathrm{GOHC}$ influence the hydrological cycle, leading to changes in continental water storage, which partly compensates for thermosteric volume changes (Ngo-Duc and others, 2005; Grinsted and others, 2007).

\section{Antarctic ice sheet response}

Wingham and others (2006) discuss Antarctic mass balance using satellite radar altimetry over the period 1993-2003. They find virtually no significant trend over this time. Estimates based on outflow velocity changes in glaciers using interferometric synthetic aperture radar (InSAR; Rignot and others, 2008b) suggest an increase in mass loss, but with very large error bars, from $112 \pm 92 \mathrm{Gta}^{-1}$ in 1996 to $196 \pm 92 \mathrm{Gt} \mathrm{a}^{-1}$ in 2006. Since 2003, Gravity Recovery and Climate Experiment (GRACE) estimates indicate significant mass loss (Velicogna, 2009), which taken together with the altimetry and InSAR data (Rignot and others, 2008b) suggests accelerating loss of ice. Indeed given a mass loss of $104 \mathrm{Gta}^{-1}$ in 2002, $247 \mathrm{Gta}^{-1}$ in 2009 and an acceleration of $-26 \mathrm{Gta}^{-2}$, mass loss would have been zero in 2000, in reasonable agreement with the altimeter and InSAR results. Indeed estimates of negative mass balance from GRACE data rely on the isostatic correction applied to the Antarctic, which Velicogna (2009) acknowledges as the largest source of error in the mass-balance estimate. Recent estimates from satellite altimetry seem to contradict GRACE mass loss estimates from Antarctica. The pattern of negative mass balance from West Antarctica and more positive balance from East Antarctica is the same for both methods; however, altimetry estimates suggest that the East Antarctic ice sheet is gaining more mass than is lost by West Antarctica (personal communication from J. Zwally, 2010). Recent combined estimates of land uplift and mass loss (Wu and others, 2010) suggest that between 2002 and 2008 West Antarctica had a net loss of $99 \mathrm{Gta}^{-1}$ while East Antarctica had a net gain of $16 \mathrm{Gt} \mathrm{a}^{-1}$. There is no observational reason to propose that Antarctic mass balance was negative prior to the 1990s; however, we cannot rule out that it was positive earlier in time.

\section{CONCLUSION}

Recent (post-2003) components of the sea-level budget appear in plausible agreement with observations: steric sea level is rising at $\sim 0.6 \mathrm{~mm} \mathrm{a}^{-1}$ (ranging from $\sim 0.05 \mathrm{~mm} \mathrm{a}^{-1}$ (Levitus and others, 2009) to $1.1 \mathrm{~mm} \mathrm{a}^{-1}$ (von Schuckmann and others, 2009)). Despite large uncertainties in steric component, the agreement between the modeled TS and that estimated from observations over the 1955-2005 period argues that despite such a wide range in recent estimates, the TS component is reasonably well constrained. Mass contributions from GRACE estimates of ice loss from Greenland and Antarctic ice sheets are $\sim 1.1 \mathrm{~mm} \mathrm{a}^{-1}$ (with uncertainties of $\sim 50 \%$ due to the short time period of the GRACE data). Small glaciers and ice caps contribute $\sim 1.3 \pm 0.2 \mathrm{~mm} \mathrm{a}^{-1}$. This compares with an observed sealevel rise rate of $\sim 3.3 \mathrm{~mm} \mathrm{a}^{-1}$. Hence the budget is in fair agreement with the observations.

The post-1955 sea-level budget, though measured over longer time intervals, is more open to question: since overall rise rates were lower, the relative magnitude of the errors associated with each component was more significant. The observed sea-level rise rate from tide gauges was $\sim 1.7 \mathrm{mma}^{-1}$ (1955-2000). Glaciological estimates for the mass balance of the ice sheets were based on limited survey methods, and only gained from satellite altimetry from about 1993. A simple addition of measured steric and glacier mass-balance components leads to a significant shortfall in the sea-level budget since 1850. The missing component of the sea-level trend since 1955 contributes $\sim 0.36 \mathrm{~mm} \mathrm{a}^{-1}$. This can, however, be well filled by estimates of mass balance of unsurveyed high-latitude small glaciers and ice caps, predominantly in the Antarctic Peninsula, which are modeled as contributing $0.28 \mathrm{~mm} \mathrm{a}^{-1}$ (Hock and others, 2009). The reasonable closure of the 1955-2005 sea-level budget suggests that total terrestrial and extra ice-sheet contributions to sea level beyond those listed in Table 1 are small for the 1955-2005 period. This closure also seems consistent with the only recent observed dynamic changes in central Greenland as it responds to marginal mass wastage (personal communication from Weili Wang, 2010).

Pre-1955 estimates exist for thermosteric and temperatelatitude glaciers and ice caps, though the mass term has much greater errors than for the post-1955 period due to the fewer glaciers measured. However, the sum of these components is also much less than required to close the budget, but much of the difference can be explained by a large mass loss of $\sim 45 \mathrm{~mm}$ between 1950 and 1960. There is also a trend in the residuals from 1850 to 1900 of $\sim 35 \mathrm{~mm}$ that is likely a response to the end of the Little Ice Age resulting in glacier wastage. Some of the pentadal variability, and the 1950s step increase may be explained by ENSO and volcanic impacts on ocean heat content, global water cycle and reductions in ice melt.

\section{ACKNOWLEDGEMENTS}

We thank G. Cogley for kindly providing the GSIC 5 year data, L. Wake and an anonymous referee for improving the manuscript, and R. Hock, J. Zwally and Weili Wang for useful discussions. The research was partly funded by NSFC No. 41076125 and China's National Key Science Program for Global Change Research (No. 2010C8950504).

\section{REFERENCES}

Antonov, J.I., S. Levitus and T.P. Boyer. 2005. Thermosteric sea level rise, 1955-2003. Geophys. Res. Lett., 32(12), L12602. (10.1029/ 2005GL023112.)

Chao, B.F., Y. Wu and Y. Li. 2008. Impact of artificial reservoir water impoundment on global sea level. Science, 320(5873), 212-214. 
Church, J.A. and N.J. White. 2006. A 20th century acceleration in global sea-level rise. Geophys. Res. Lett., 33(1), L01602. (10.1029/2005GL024826.)

Cogley, J.G. 2009. Geodetic and direct mass-balance measurements: comparison and joint analysis. Ann. Glaciol., 50(50), 96-100.

Domingues, C.M. and 6 others. 2008. Improved estimates of upperocean warming and multi-decadal sea-level rise. Nature, 453(7198), 1090-1094.

Fekete, B.M., C.J. Vörösmarty and W. Grabs. 1999. Global, composite runoff fields based on observed river discharge and simulated water balances. Koblenz, Global Runoff Data Center. (GRDC Report 22.)

Folland, C.K. and D.E. Parker. 1995. Correction of instrumental biases in historical sea surface temperature data. Q. J. $R$. Meteorol. Soc., 121(522), 319-367.

Gornitz, V. 2011. Impoundment, groundwater mining, and other hydrologic transformations: impacts on global sea level rise. In Douglas, B.C., M.S. Kearney and S.P. Leatherman, eds. Sea level rise: history and consequences. San Diego, CA, Academic Press, 97-119.

Gregory, J.M., J.A. Lowe and S.F.B. Tett. 2006. Simulated globalmean sea level change over the last half-millennium. J. Climate, 19(18), 4576-4591.

Grinsted, A., J.C. Moore and S. Jevrejeva. 2007. Observational evidence for volcanic impact on sea level and the global water cycle. Proc. Natl. Acad. Sci. USA (PNAS), 104(50), $19,730-19,734$

Grinsted, A., J.C. Moore and S. Jevrejeva. 2009. Reconstructing sea level from paleo and projected temperatures 200 to 2100 AD. Climate Dyn., 34(4), 461-472.

Hock, R., M. de Woul, V. Radiá and M. Dyurgerov. 2009. Mountain glaciers and ice caps around Antarctica make a large sea-level rise contribution. Geophys. Res. Lett., 36(7), L07501. (10.1029/ 2008GL037020.)

Ishii, M. and M. Kimoto. 2009. Reevaluation of historical ocean heat content variations with time-varying XBT and MBT depth bias corrections. J. Oceanogr., 65(3), 287-299.

Ishii, M., M. Kimoto, K. Sakamoto and S.-I. Iwasaki. 2006. Steric sea level changes estimated from historical subsurface temperature and salinity analyses. J. Oceanogr., 61(2), 155-170.

Jevrejeva, S., A. Grinsted, J.C. Moore and S. Holgate. 2006. Nonlinear trends and multi-year cycle in sea level records. J. Geophys. Res., 111(C9), C09012. (10.1029/2005JC003229.)

Jevrejeva, S., J.C. Moore, A. Grinsted and P.L. Woodworth. 2008a. Recent global sea level acceleration started over 200 years ago. Geophys. Res. Lett., 35(8), L08715. (10.1029/2008GL033611.)

Jevrejeva, S., J.C. Moore and A. Grinsted. 2008b. Relative importance of mass and volume changes to global sea level rise. J. Geophys. Res., 113(D8), D08105. (10.1029/2007JD009208.)

Jevrejeva, S., A. Grinsted and J.C. Moore. 2009. Anthropogenic forcing dominates sea level rise since 1850. Geophys. Res. Lett., 36(20), L20706. (10.1029/2009GL040216.)

Jevrejeva, S., J.C. Moore and A. Grinsted. 2010. How will sea level respond to changes in natural and anthropogenic forcings by 2100? Geophys. Res. Lett., 37(7), L07703. (10.1029/ 2010GL042947.)

Kaplan, A., Y. Kushnir and M.A. Cane. 2000. Reduced space optimal interpolation of historical marine sea level pressure. J. Climate, 13(16), 2987-3002.

Kaser, G., J.G. Cogley, M.B. Dyurgerov, M.F. Meier and A. Ohmura. 2006. Mass balance of glaciers and ice caps: consensus estimates for 1961-2004. Geophys. Res. Lett., 33(19), L19501. (10.1029/2006GL027511.)

Lettenmaier, D.P. and P.C.D. Milly. 2009. Land waters and sea level. Nature Geosci., 2(7), 452-454.

Levitus, S., J.I. Antonov and T.P. Boyer. 2005. Warming of the world ocean, 1955-2003. Geophys. Res. Lett., 32(2), L02604. $(10.1029 / 2004 G L 021592$.
Levitus, S., J.I. Antonov, T.P. Boyer, R.A. Locarnini, H.E. Garcia and A.V. Mishonov. 2009. Global ocean heat content 1955-2008 in light of recently revealed instrumentation problems. Geophys. Res. Lett., 36(7), L07608. (10.1029/2008GL037155.)

Milly, P.C.D., A. Cazenave and C. Gennero. 2003. Contribution of climate-driven change in continental water storage to recent sea-level rise. Proc. Natl. Acad. Sci. USA (PNAS), 100(23), $13,158-13,161$.

Mitrovica, J.X., J. Wahr, I. Matsuyama, A. Paulson and M.E. Tamisiea. 2006. Reanalysis of ancient eclipse, astronomic and geodetic data: a possible route to resolving the enigma of global sea-level rise. Earth Planet. Sci. Lett., 243(3-4), 390-399.

Ngo-Duc, T., K. Laval, J. Polcher, A. Lombard and A. Cazenave. 2005. Effects of land water storage on global mean sea level over the past half century. Geophys. Res. Lett., 32(9), L09704. (10.1029/2005GL022719.)

Oerlemans, J., M. Dyurgerov and R.S.W. van de Wal. 2007. Reconstructing the glacier contribution to sea-level rise back to 1850. Cryosphere, 1(1), 59-65.

Peltier, B. 2001. Global glacial isostatic adjustment and modern instrumental records of relative sea level history. In Douglas, B.C., M.S. Kearney and S.P. Leatherman, eds. Sea level rise: history and consequences. San Diego, CA, Academic Press, 65-95.

Rignot, E., J.E. Box, E. Burgess and E. Hanna. 2008a. Mass balance of the Greenland ice sheet from 1958 to 2007. Geophys. Res. Lett., 35(20), L20502. (10.1029/2008GL035417.)

Rignot, E. and 6 others. 2008b. Recent Antarctic ice mass loss from radar interferometry and regional climate modelling. Nature Geosci., 1(2), 106-110.

Robock, A. 2000. Volcanic eruptions and climate. Rev. Geophys., 38(2), 191-219.

Sahagian, D. 2000. Global physical effects of anthropogenic hydrological alterations: sea level and water redistribution. Global Planet. Change, 25(1-2), 39-48.

Shiklomanov, A.I. 1997. Comprehensive assessment of the freshwater resources of the world: assessment of water resources and water availability in the world. Geneva, World Meteorological Association. (Report E/CN.17/1997/9.)

Stenchikov, G.L., G. Delworth, V. Ramaswamy, R.J. Stouffer, A. Wittenberg and F. Zeng. 2009. Volcanic signals in oceans. J. Geophys. Res., 114(D16), D16104. (10.1029/2008JD011673.)

Trenberth, K.E. 2009. An imperative for climate change planning: tracking Earth's global energy. Curr. Opin. Environ. Sustain., 1(1), 19-27.

Trenberth, K.E. and A. Dai. 2007. Effects of Mount Pinatubo volcanic eruption on the hydrological cycle as an analog of geoengineering. Geophys. Res. Lett., 34(15), L15702. (10.1029/ 2007GL030524.)

Velicogna, I. 2009. Increasing rates of ice mass loss from the Greenland and Antarctic ice sheets revealed by GRACE. Geophys. Res. Lett., 36(19), L19503. (10.1029/2009GL040222.)

Vermeer, M. and S. Rahmstorf. 2010. Global sea level linked to global temperature. Proc. Natl. Acad. Sci. USA (PNAS), 106(51), 21,527-21,532.

von Schuckmann, K., F. Galliard and P.-Y. Le Traon. 2009. Global hydrographic variability patterns during 2003-2008. J. Geophys. Res., 114(C9), C09007. (10.1029/2008JC005237.)

Wingham, D.J., A. Shepherd, A. Muir and G.J. Marshall. 2006. Mass balance of the Antarctic ice sheet. Philos. Trans. R. Soc London, Ser. A, 364(1844), 1627-1635.

Woodworth, P.L. and R. Player. 2003. The Permanent Service for Mean Sea Level: an update to the 21 st century. J. Coastal Res. 19(2), 287-295.

Wu, X.M. and 8 others. 2010. Simultaneous estimation of global present-day water transport and glacial isostatic adjustment. Nature Geosci., 3(9), 642-646. 